\title{
A CONSTRuÇão Transitiva no PORTUguês brasileiro: ASPECTOS COGNITIVO-INTERACIONAIS
}

\author{
Nedja Lima de Lucena ${ }^{1}$
}

\section{RESUMO}

Este artigo discute aspectos cognitivo-interacionais relacionados a uma subclasse de construções de estrutura argumental: a Construção Transitiva. Alinha-se teoricamente à Linguística Funcional Centrada no Uso que abriga a concepção de que as línguas são moldadas pela complexa interação de princípios cognitivos e funcionais. A partir da análise de dados empíricos, a pesquisa conclui que a Construção Transitiva é altamente esquemática e produtiva, em termos de types e de tokens, o que justifica o alto número de verbos licenciados por essa construção, e atesta que a aproximação ou afastamento entre as instanciações são motivados preponderantemente por propriedades semânticas.

Palavras-chave: Gramática de Construções; Construções de estrutura argumental; Construção Transitiva; Linguística Funcional Centrada no Uso.

\begin{abstract}
This article discusses cognitive and interactional aspects related to argument structure construction subclass: the Transitive Construction. It is theoretically aligned with Usage-based Linguistics, which holds the conception that the languages are shaped by the complex interaction of cognitive and functional principles. From the analysis of empirical data, the research has concluded that the transitive construction is highly schematic and productive, in terms of types and tokens, which justifies the high number of verbs licensed by this construction, as well as it attests the proximity or distancing amongst the instances that are especially motivated by semantic properties.
\end{abstract}

1 Universidade Federal do Amapá (UNIFAP). E-mail: lucenedja@gmail.com 
Keywords: Construction Grammar; Argument structure Constructions; Transitive Construction; Usage-based Linguistics.

\section{Introdução}

A noção de construção ${ }^{2}$, pareamento entre forma e significado, está presente em diversos estudos linguísticos como se pode ver em Lakoff(1987), Fillmore (1988) e Fillmore, Kay e O'Connor (1988)³. No entanto, essa noção se ampliou e ganhou ênfase a partir da agenda de trabalhos propostos por Goldberg (1995; 2006), Croft (2001), Tomasello (1998; 2003; 2005), Traugott (2008), Bybee (2010), Traugott e Trousdale (2013), inter alia. Esses autores compartilham a noção de que as construções gramaticais devem ser tomadas como as unidades primárias da língua.

O fato é que a Gramática de Construções (GC) tem fornecido um profícuo diálogo entre os estudos de orientação funcionalista e cognitivista. Além disso, as pesquisas alicerçadas na abordagem construcional têm gerado um panorama descritivo das construções das línguas naturais. No Brasil, os trabalhos de Rosário e Oliveira (2016), Furtado da Cunha (2015), Ciríaco (2011), Salomão e Miranda (2009), Oliveira (2009), Torrent (2008), Rodrigues (2006), dentre outros, são exemplos de estudos que descrevem construções do português brasileiro.

Nessa linha, filiado ao quadro teórico da Linguística Funcional Centrada no Uso, este artigo discute um tipo de construção de estrutura argumental ${ }^{4}$, a Construção Transitiva (O professor pegou um béquer). São examinadas as instanciações dessa construção, compostas por orações simples formadas sintaticamente por Sujeito (S) - Verbo (V) - Objeto Direto (OD) 5 .

A Construção Transitiva corresponde a um tipo de construção que ocorre em diversas línguas, de maneira que na presente pesquisa focaliza-se o Português brasileiro. Em relação à forma, possui

2 O termo construção é utilizado pela própria gramática tradicional para se referir a fenômenos como construção passiva, reflexiva e impessoal. O termo também faz parte da história do gerativismo, no entanto, com outro significado. Nessa abordagem, a construção estava relacionada a regras específicas da gramática transformacional, bem como servia de pano de fundo para se pensar em princípios gerais (SALOMÃO; MIRANDA, 2009).

3 De certo modo, esses estudos são desdobramentos dos trabalhos prógonos de Fillmore (1968), The case for case reopened, e de Lakoff (1977), Linguistics gestalts. A expressão Gramática de Construção foi cunhada por Fillmore et al. (1988).

$4 \mathrm{O}$ conceito de estrutura argumental muitas vezes é tratado nas gramáticas tradicionais e nas gramáticas descritivas como sinônimo de regência verbal, valência verbal e transitividade (cf. CUNHA; CINTRA, 1985; SAID ALI, 1971; NEVES, 2000; PERINI, 1995, entre outros).

5 As orações transitivas indiretas não estão contempladas nesta análise. 
arranjo sintático que se caracteriza, na maioria dos casos, por dois argumentos em torno de um verbo, sendo que esses correspondem às relações gramaticais de Sujeito e Objeto Direto. Esse arranjo está diretamente associado a um sentido central que implica uma entidade Agente que age para causar uma mudança de estado ou de condição numa entidade Paciente (GOLDBERG, 1995; 2006; GIVÓN, 2001; TAYLOR, 2003).

Ocorre que, com base no sentido central da Construção Transitiva, o falante estende sua moldura sintática para abarcar outros tipos de eventos que se afastam do significado prototipicamente a ela associado. Assim, para descrever essa construção, é necessário o exame de dados empíricos oriundos de situações sociocomunicativas, com o intuito de observar como se caracterizam as suas instanciações.

Desse modo, em termos metodológicos, foram coletadas 321 orações advindas de diversos corpora $^{6}$. A partir desses dados, foi realizado um exame dos atributos sintático-semânticos e discursivo-pragmáticos das orações coletadas.

O artigo está organizado em três seções seguidas a esta introdução: na primeira, são discutidos aspectos referentes ao quadro teórico da Linguística Funcional Centrada no Uso, focalizando a GC; posteriormente, são assinaladas reflexões sobre a noção de construções de estrutura argumental; na seção seguinte, são apontados os resultados da análise da Construção Transitiva. Por último, são tecidas algumas considerações finais.

\section{A Linguística Funcional Centrada no Uso e a Gramática de Construções}

A descrição da Construção Transitiva desenvolvida neste artigo alinha-se aos pressupostos teórico-metodológicos da Linguística Funcional Centrada no Uso (LFCU). Em linhas gerais, essa abordagem teórica abriga: (a) a compreensão de que a língua está fundamentada como um complexo mosaico de atividades cognitivas e sociocomunicativas, (b) o entendimento de que as habilidades linguísticas podem ser tomadas e apreendidas do mesmo modo que outras habilidades cognitivas e (c) a ideia de que a língua consiste de um inventário de construções utilizadas na comunicação (TOMASELLO, 1998; BYBEE, 2010).

6 Corpus Discurso \& Gramática: a língua falada e escrita na cidade do Natal (Corpus D\&G); Banco Conversacional de Natal (BCN); Revista Istoé; Blogs Vida Materna e Santa Dieta (BVM / BSD); Contos As mãos do meu filho (CMF) e Passeio Noturno (CPN). 
À luz da LFCU, as estruturas linguísticas são motivadas e ritualizadas a partir de fatores discursivo-funcionais sujeitos a motivações cognitivas subjacentes. Em outras palavras, as línguas são desenhadas pela complexa simbiose entre princípios cognitivos e interacionais que desempenham um papel na mudança linguística, na aquisição e no uso da língua (FURTADO DA CUNHA; BISPO; SILVA 2013). Sob essa ótica, o uso está associado à complexa arquitetura cognitiva da mente humana, que é capaz de selecionar, recortar, classificar, isto é, categorizar as entidades e eventos que nos cercam.

Desse modo, a língua pode ser assinalada como um sistema adaptativo complexo, constituído simultaneamente de padrões regulares e emergentes, a qual serve aos falantes engajados em experiências sociointerativas. Os padrões linguísticos ritualizados e em emergência constituem a gramática. Segundo Bybee (2010), “a gramática pode ser pensada como a organização cognitiva de uma experiência com a linguagem” (p. 9).

$\mathrm{Na}$ esteira da LFCU reside o interesse pela GC, sobretudo, a partir das investigações de Goldberg (1995; 2006). A construção une, em par, forma (morfossintática e fonético-fonológica) alinhada a significado (funções semântica, pragmática e discursiva). Assumir a perspectiva construcional implica o reconhecimento de que a gramática corresponde a uma grande rede de construções. Nesse viés, não há estrita divisão entre léxico e gramática, de forma que estes são tomados como um continuum. De maneira geral, todas as abordagens construcionais enxergam a gramática como um arcabouço holístico, ou seja, nenhum nível é autônomo ou central (LANGACKER, 2008; SALOMÃO; MIRANDA, 2009; TRAUGOTT; TROUSDALE, 2013).

As construções se estabelecem a partir da frequência com que os falantes as usam, tornandose uma unidade de processamento. Nesse seguimento, para abarcar determinados usos, os falantes exploram os recursos disponíveis em seu repertório, a fim de consolidar seus objetivos comunicativos. Em outras palavras, há padrões que ultrapassam o que é predizível pelas regras gramaticais, de modo que a elucidação desses deve ser investigada no âmbito da cognição e da comunicação (GOLDBERG, 2006; BYBEE, 2010).

Variáveis em complexidade e esquematicidade, as construções se configuram em unidades, desde morfemas, palavras, estruturas frasais mais complexas até padrões textuais (ÖSTMAN; FRIED, 2005). Para elucidar a afirmação, Goldberg (cf. 2006, p. 5) assinala que, no inglês, morfemas, como -ing, palavras, como avocado e anaconda, e padrões frasais, a exemplo da Ditransitiva he gave her a 
fish taco são tomados como construções.

Goldberg (2006) e Langacker (2008) explicam que as construções são concebidas como unidades simbólicas, convencionalizadas, organizadas em redes e tomadas basicamente como esquemas cognitivos do mesmo tipo dos que existem em outros domínios da cognição. Na mesma linha, Traugott e Trousdale (2013, p. 1) resumem essa ideia ao afirmarem que as construções "são unidades em que algum aspecto do signo é tão idiossincrático (GOLDBERG, 1995) ou tão frequente (GOLDBERG, 2006) que o signo é armazenado como um par forma-significado na mente do falante". Além disso, grande parte das construções é parcialmente esquemática, contendo, assim, posições pré-definidas essenciais para a configuração do exemplar prototípico e posições abertas que podem abarcar uma categoria de itens semanticamente delineados (BYBEE, 2010).

Vale ressaltar que a abordagem construcional enfatiza que construções mais comuns às línguas, como a Ditransitiva, a Transitiva e a Passiva, convivem juntamente com outras, mais específicas e particulares de uma dada língua. Dito de outra maneira, há eventos codificados em várias línguas (por exemplo, causação, posse, negação, entre outros), no entanto, o modo como tais eventos são empacotados linguisticamente, em termos de instanciações das construções, pode ser altamente variável e singular.

As construções podem admitir uma família de distintos sentidos que se relacionam de algum modo. Traugott e Trousdale (2013) defendem que uma determinada construção pode ser pensada hierarquicamente em termos de três níveis: esquemas, subesquemas e microconstruções. Em termos decrescentes, o esquema corresponde à generalização mais abstrata e virtual, que está no topo da hierarquia. Abaixo dele, está o subesquema, relacionado ao sentido central e à forma prototípicos da construção, bem como outros sentidos relacionados. Seguidamente, situam-se as microconstruções, que contemplam tipos individuais da construção, instanciadas por construtos (tokens). Os autores exemplificam a hierarquia a partir do caso da microconstrução may, que pertence ao subesquema modal e, por conseguinte, ao esquema dos auxiliares (cf. TRAUGOTT; TROUSDALE, 2013).

Assentado, em especial, na abordagem construcional de Goldberg (1995; 2006) este artigo intenta descrever as manifestações sintático-semânticas da Construção Transitiva. Para tanto, é necessário explanar o interesse pelas construções que evocam os significados oracionais básicos em uma língua, as construções de estrutura argumental, que estão no cerne da investigação da GC, como 
pode ser observado a seguir.

\section{Construções de estrutura argumental}

A noção de estrutura $\operatorname{argumental}^{7}$ diz respeito à inter-relação entre verbos e sintagmas nominais na oração, de maneira que a quantidade e os papéis que os nomes desempenham compõem a estrutura argumental de um dado verbo (CHAFE, 1979; FILLMORE, 1977). Mais precisamente, a estrutura argumental é um fenômeno multidimensional, no qual interagem aspectos semânticos, sintáticos, morfológicos, tipológicos, diacrônicos, relacionados à aquisição, à cognição e, sobretudo, à pragmática. Por exemplo, um sintagma nominal numa determinada oração pode exibir múltiplas dimensões: do ponto de vista gramatical, pode ser um sujeito transitivo; semanticamente, um humano experienciador; do ponto de vista morfológico, um pronome; e pragmaticamente, uma informação dada (DU BOIS; KUMPF; ASHBY, 2003; FURTADO DA CUNHA, 2009).

Consoante Goldberg (1995), as construções de estrutura argumental existem independentemente de verbos particulares, ou seja, possuem significado próprio e estão parcialmente atreladas às palavras que a compõem. Sua tese ancora-se no fato de que um mesmo verbo pode ocorrer em diferentes construções de estrutura argumental, como é o caso, no inglês, de slice (fatiar/partir) em He sliced the bread (Construção Transitiva), Pat sliced the carrots into the salad (Construção de Movimento Causado) e Pat sliced Chris a piece of pie (Construção Ditransitiva).

Desse modo, uma determinada construção licencia os verbos que podem ocorrer com ela. Isso significa que construções e verbos interagem de algum modo; sendo assim, é necessário considerar novos usos de verbos em construções particulares, bem como analisar a semântica e/ou informação sintática especificada pelo verbo (GOLDBERG, 2006).

As construções de estrutura argumental têm papéis argumentais que podem se conectar diretamente a um conjunto de diferentes papéis semânticos (como Agente, Paciente, Tema, Estativo, Recipiente, Locativo etc.). Nessa linha, o sentido do verbo está atrelado a um frame semântico que em parte especifica os argumentos associados ao significado de um dado verbo.

7 A noção de estrutura argumental tem sua gênese na Filosofia (cf. FREGE, [1978] 2009) e sua discussão está presente em diversos trabalhos, dentre os quais recomenda-se: Thompson e Hopper (2001), Du Bois et al. (2003) e Furtado da Cunha $(2009 ; 2015)$. 
Assim posto, segundo Goldberg (1995), fundem-se os papéis argumentais (da construção) e os papéis participantes (do verbo), motivados pelo princípio da coerência semântica e o princípio da correspondência. O primeiro demonstra que apenas papéis compatíveis semanticamente podem se fundir; já o segundo apresenta a ideia de que cada papel participante do verbo deve ser fundido com - e expresso por - um papel argumental da construção.

A integração entre os papéis aplica-se aos argumentos mais centrais ou nucleares (especificados por relações gramaticais como Sujeito, Objeto Direto e Objeto Indireto), os quais têm alta proeminência discursiva $^{8}$. A interface entre a construção e o verbo mostra que a semântica lexical e a pragmática discursiva se alinham, ou seja, os participantes que são importantes no significado do verbo são aqueles que são relevantes para o discurso.

A perspectiva construcional expressa alguns benefícios para a investigação das construções de estrutura argumental: (a) descarte de sentidos implausíveis para um verbo; (b) entendimento de que o sentido do verbo é integrado ao sentido da construção; (c) noção de que a construção tem significado próprio, convencional e esquemático independente de verbos particulares e (d) a noção de que os itens lexicais contribuem para o significado das orações, mas não são responsáveis por todo o significado (GOLDBERG, 1995; FERRARI, 2011).

É válido assinalar que, por ser basilar para entendimento da língua, a investigação das construções de estrutura argumental é fundamental para explicar como as estruturas gramaticais ritualizam-se e emergem na dinâmica do discurso. Além de que a observação dessas construções é um ponto chave para compreender como se dá a interação entre léxico e gramática.

\section{Configuração da construção transitiva: uma abordagem centrada no uso}

A Construção Transitiva (CT) é uma construção que implica o significado básico $X$ afetar $Y$, sendo codificada como Sujeito (S) Verbo (V) Objeto Direto (OD), conforme o seguinte esquema representativo:

8 Essa regra não é rígida. Goldberg explica que, se um verbo tem três argumentos, uma posição pode ser preenchida por um argumento oblíquo, isto é, mais periférico. A autora ainda descreve possibilidades de restrições quanto a argumentos e adjuntos (cf. GOLDBERG, 2006, p. 42). 


\section{AFETAR Y}

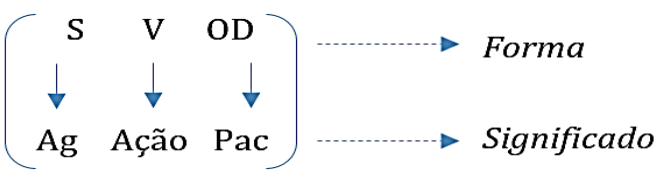

Figura 1 - Esquema da CT

O evento denotado pela CT é aquele em que há dois participantes: um Agente e um Paciente. O primeiro direciona um fluxo de energia que é transmitido e causa alguma mudança, seja de condição, de estado ou de localização, no segundo, que é impactado por essa energia (TALMY, 1988; LANGACKER, 2008). Observe-se a seguinte ocorrência:

(1) Cortei uma raposinha que tinha no livro de Layce. (BCN, Conversa 8, fala).

A oração em (1) é formada pelo verbo cortar que perfila dois papéis participantes: uma entidade que corta e uma entidade que é cortada. Esses papéis correspondem aos papéis argumentais da CT, Agente e Paciente. (1) é composta por S $(\varnothing=\mathrm{eu}$ ) e OD (uma raposinha), que acomodam, respectivamente, os papéis semânticos de Agente e Paciente. A correspondência entre a moldura sintática e a moldura semântica é o que define a CT, conforme ilustra a Figura 1.

Prototipicamente, a CT licencia verbos do tipo semântico ação-processo cuja característica é expressar uma mudança de estado, condição ou locação de um paciente, causada por um sujeito animado e intencional (BORBA, 1996). Foram encontradas 161 ocorrências de verbos ação-processo, distribuídos em 91 types (por exemplo, fazer, pegar, comprar, abrir, enterrar, trancar etc), o que corresponde a maior parte dos dados. Desses, os verbos mais frequentes foram fazer (35 ocorrências) e pegar (23 ocorrências). Veja-se:

(2) Fizemos um levantamento, que mostrei ao Conselho Federal de Medicina, com mais de dez casos de mortes e complicações graves atribuídas a cirurgiões plásticos. (Revista Istoé, 11Jul/2012, escrita).

(3) Ele pegou um cano e assustou o gato (Corpus D\&G, p. 46, escrita)

Em (2), o $\mathrm{S}(\varnothing=$ nós) realiza uma ação (fazer), portanto é Agente, que causa a criação de uma 
entidade (um levantamento - objeto efetuado ${ }^{9}$ ), que não existia e passa a existir. Na oração em (3), o $\mathrm{S}$ (ele) intencionalmente afeta (ação expressa por pegar) e causa uma mudança de lugar da entidade OD - Paciente (um cano) que é deslocado de um lugar para as mãos do Agente. Desse modo, pode-se dizer que a moldura semântica de fazer e de pegar é análoga à semântica da $\mathrm{CT}$, de maneira que os eventos denotados por fazer e pegar são instanciações do evento relacionado à CT.

Sob a ótica de Langacker (2008), as línguas humanas podem codificar eventos a partir de duas orientações, uma agentiva e outra temática ${ }^{10}$, de maneira que cada língua recorta qual dessas orientações será prototípica. No caso do Português brasileiro, a orientação agentiva é predominante: a tendência é de que o Agente seja foco de atenção e preencha, ainda, a posição de Sujeito. Segundo Bybee (2010), a alta frequência de uso de um construto é o que contribui para modelar a representação mental da construção que ele instancia.

Sob a perspectiva de Goldberg (1995), as construções se ligam a uma família de sentidos intimamente relacionados, isso permite que a construção estenda seu sentido para abarcar usos que se afastam do exemplar prototípico. Nesse viés, há elos relacionais entre as instanciações da construção, como ocorre com a CT, que preserva suas especificações sintáticas e estende sua moldura semântica, como pode ser observado nos dados (4-8) a seguir. Sendo assim, a agentividade e o afetamento podem ser pensados em termos de gradualidade (+/- Agente/Paciente).

Nos dados analisados, foram encontradas 81 ocorrências de verbo de $a c ̧ \tilde{a} o$, as quais correspondem a um percentual de $25,2 \%$ do total de ocorrências. Caracterizado por expressar uma atividade, física ou não, realizada por um Agente na posição S, esse tipo de verbo "indica um fazer por parte do sujeito" (BORBA, 1996, p. 58). Somam-se a esse tipo de verbo os papéis semânticos de Agente para o S e Tema ${ }^{11}$ para o OD, conforme ilustra a ocorrência:

9 Givón (2001) explica que o afetamento do objeto pode ocorrer de maneira parcial ou total como em She washed his shirt (Ela lavou a camisa dele) e They demolished the house (Eles demoliram a casa), respectivamente; ou ainda, o objeto pode ser efetuado pela ação verbal, ou seja, criado a partir dessa ação She made a dress (Ela fez um vestido). Seguindo a proposta givoniana, a denominação Paciente aplica-se ao OD afetado e efetuado.

10 Agent orientation e theme orientation, nos termos do autor. Segundo ele, Tema está associado a uma série de papéis semânticos, tais como: Paciente, Experienciador e Zero. Para maior detalhamento, consultar Langacker (2008, p. 366).

11 Esse papel, tal como utilizado aqui, designa o participante do evento que não é afetado nem efetuado pela ação verbal, mas faz parte da moldura do verbo. Pode corresponder ao papel Objetivo (ou objeto estativo) utilizado por Cançado (2005). 
(4) Examinei o carro na garagem (CPN, escrita).

A ocorrência em (4) denota um evento em que S $(\varnothing=e u)$ é Agente, no entanto, a ação praticada (examinar) não desencadeia nenhuma mudança no referente OD (o carro), sendo este Tema [Paciente].

Segundo Borba (1996), há casos, ainda, de verbos cuja ação é uma atividade mental e cujo S possui menos propriedades agentivas, sendo tomado como um Experienciador. Veja-se o dado:

(5) O Pelé também esqueceu os documentos..." (BCN, Conversa 2, fala).

O caso em (5) expressa um evento em que $\mathrm{S}$ (O Pelé) não apresenta propriedades de Agente (como intencionalidade e controle), uma vez que esquecer é uma atividade que ocorre, a princípio, sem querer. Além disso, não há afetamento no OD (os documentos). De acordo com Borba, quando os verbos denotam uma atividade mental (psicológica ou perceptual), o S é um Experienciador [Agente], ao passo que o OD é o Estímulo [- Paciente] para essa experiência.

$\mathrm{Na}$ amostra coletada, foram constatadas ocorrências com verbo de enunciação ou dicendi, como em (6):

(6) Quando o professor saiu... eu chamei umas duas colegas minhas pra mostrar a experiência que eu tinha achado fantástico (Corpus D\&G, p. 50, fala).

No caso acima, a ação de dizer (chamar) praticada por S (eu) é intencional e o OD (umas duas colegas minhas), a priori, não é afetado diretamente pela ação, nem efetuado por ela, já que seu referente preexiste à enunciação. No entanto, Furtado da Cunha (2013), ao examinar a Construção Ditransitiva, aponta que verbos dicendi também são licenciados pela construção. Explica que esses verbos denotam uma atividade que, via extensão metafórica, é interpretada como uma transferência de quem diz > para quem se diz. No mesmo viés, a CT licencia tais verbos, especialmente, porque conforma aquilo que é dito ao papel argumental Paciente, sendo este uma contribuição da própria construção.

Os dados apresentam, ainda, orações com o verbo do tipo semântico processo, cuja característica 
é expressar um acontecer, ou seja, um evento ou conjunto de eventos que afetam um S Paciente (BORBA, 1996). São atestadas 29 ocorrências (9\% dos dados) com esse tipo verbal, de maneira que correspondem ao tipo semântico menos frequente no material investigado. Um dado pode ser visto em:

(7) [O Brasil] Ele enfrenta uma transformação muito grande. (Corpus D\&G, p. 85, fala)

Como se pode observar, o referente de $\mathrm{S}($ Ele $=$ Brasil $)$ é Paciente do processo denotado pelo verbo (enfrentar), enquanto o OD (uma transformação muito grande) é Tema [- Paciente] do processo.

Na descrição feita até aqui, é possível perceber que as instanciações se afastam progressivamente do exemplar prototípico. Esse afastamento também é verificável em instanciações com verbos do tipo semântico estado. Para Borba (1996), esse tipo de verbo é definido como aquele em que não há a expressão de uma ação ou de um processo, de maneira que o que se exibe é uma propriedade (estado, condição, situação) de um elemento $\mathrm{S}$.

(8) [Sobre alimentos] Esses contêm magnésio, clorofila e são ricas em antioxidantes (BVM, 06/11/2012, escrita, inserção minha).

A oração em (8) apresenta um verbo (conter) que designa uma propriedade de $\mathrm{S}$ (esses $=$ alimentos), enquanto o OD (magnésio, clorofila) assinala especificamente essa propriedade. S e OD evidenciam, portanto, os papéis semânticos de Suporte de Propriedade (BORBA, 1996) e Estativo (CANÇADO, 2005), respectivamente. Casos como esse correspondem a 50 (15,5\%) ocorrências nos dados coletados.

Todas as instanciações averiguadas aqui herdam a grade sintática da CT ao passo que a diferença entre elas ocorre majoritariamente no nível da semântica. Dado que na abordagem construcional não há divisão estrita entre léxico e gramática, bem como entre semântica e pragmática, é natural que a semântica das construções contemple as informações pragmáticas a elas associadas (GOLDBERG, 1995).

Em relação aos sentidos arrolados para a CT nos corpora investigados, foram encontrados os seguintes: 
a. $\mathrm{X}$ afetar $\mathrm{Y}\{\mathrm{S}$ [V Ação-processo $\mathrm{OD}\}-$ Sentido central

$[\mathrm{X} \varnothing=\mathrm{eu}]$ apaguei [Y as luzes do carro $]^{12}$

b. $\quad \mathrm{X}$ agir $\mathrm{Y}\{\mathrm{S}[\mathrm{V}$ Ação] OD $\}$

$[\mathrm{X} \varnothing=$ nós $]$ subimos [Y uma duna $]^{13}$

c. $\mathrm{X}$ experienciar Y $\{\mathrm{S}[\mathrm{V}$ Ação (psicológica/sensorial) $] \mathrm{OD}\}$

$[\mathrm{X} \varnothing=$ nós $]$ ouvimos [Y o coraçãozinho do bebê $]^{14}$

d. $\quad \mathrm{X}$ dizer $\mathrm{Y}\{\mathrm{S}[\mathrm{V}$ Ação (dicendi) $] \mathrm{OD}\}$

[X Diamond] divulgou [Y dados $]^{15}$

e. $\mathrm{X}$ acontecer $\mathrm{Y}\{\mathrm{S}[\mathrm{V}$ Processo $] \mathrm{OD}\}$

[X O Brasil] enfrenta [Y uma transformação] $]^{16}$

f. $\quad \mathrm{X}$ possuir $\mathrm{Y}\{\mathrm{S}[\mathrm{V}$ Estado] OD $\}$

$[\mathrm{X} \mathrm{Eu}]$ tenho $[\mathrm{Y} \text { uma série de plantas }]^{17}$

Na ótica de Bybee (2010), a adesão de um novo membro a uma categoria pode ocorrer a partir da interação de duas dimensões: semelhança e frequência. Considerando que as construções são objetos linguísticos convencionalizados, a frequência de ocorrência de um dado padrão pode influenciar significativamente a categorização na linguagem.

\footnotetext{
12 CPN, escrita.

13 Corpus D\&G, p. 169, escrita.

14 BVM, 06/11/12, escrita.

15 Revista Istoé, 11Jul/2012, escrita.

16 Revista Istoé, 11Jul/2012, escrita.

17 Corpus D\&G, p. 57, fala.
} 
Os usos convencionalizados de formas linguísticas refletem situações também rotinizadas. Dessa maneira, tanto a forma quanto o sentido são facilmente acessíveis e se configuram como bons modelos para recrutar novos membros. Nesse sentido, a CT é produtiva, uma vez que seu padrão pode ser aplicado para abarcar novos enunciados, como atestam os dados.

Em relação aos papéis semânticos atribuídos a S e OD nos tokens da CT, cada sentido atribuído à construção conforma papéis semânticos distintos, conforme se pode observar no quadro 1, a seguir, que sumariza os resultados:

\begin{tabular}{|c|c|c|}
\hline Sentidos observados nas orações coletadas & Papel semântico do $\mathrm{S}$ & Papel semântico do OD \\
\hline $\begin{array}{c}\text { Sentido A } \\
X \text { afetar } Y \\
\{\mathrm{~S}[\mathrm{~V} \text { Ação-processo }] \mathrm{OD}\}\end{array}$ & + Agente & + Paciente \\
\hline $\begin{array}{c}\text { Sentido B } \\
X \text { agir } Y \\
\{\mathrm{~S}[\mathrm{~V} \text { Ação] OD }\}\end{array}$ & + Agente & $\begin{array}{c}\text { - Paciente } \\
\text { (Tema) }\end{array}$ \\
\hline $\begin{array}{c}\text { Sentido C } \\
\text { X experienciar } Y \\
\{\text { S }[\text { V Ação }(\text { psicológica/sensorial })] \mathrm{OD}\}\end{array}$ & $\begin{array}{c}\text { - Agente } \\
\text { (Experienciador) }\end{array}$ & $\begin{array}{l}\text { - Paciente } \\
\text { (Estímulo) }\end{array}$ \\
\hline $\begin{array}{c}\text { Sentido D } \\
X \text { dizer } Y \\
\{\mathrm{~S}[\mathrm{~V} \text { Ação }(\text { dicendi })] \mathrm{OD}\}\end{array}$ & + Agente & + Paciente \\
\hline $\begin{array}{c}\text { Sentido E } \\
X \text { acontecer } Y \\
\{\mathrm{~S}[\mathrm{~V} \text { Processo }] \mathrm{OD}\}\end{array}$ & $\begin{array}{l}\text { - Agente } \\
\text { (Paciente) }\end{array}$ & $\begin{array}{c}\text { - Paciente } \\
\text { (Tema) }\end{array}$ \\
\hline $\begin{array}{c}\text { Sentido } \mathrm{F} \\
Y \text { possuir } Y \\
\{\mathrm{~S}[\mathrm{~V} \text { Estado] } \mathrm{OD}\}\end{array}$ & $\begin{array}{c}\text { - Agente } \\
\text { (Suporte de propriedade) }\end{array}$ & $\begin{array}{l}\text { - Paciente } \\
\text { (Estativo) }\end{array}$ \\
\hline
\end{tabular}

Quadro 1 - Papéis semânticos observados nas ocorrências

Em síntese, a CT é esquemática e produtiva, em termos de types e tokens, bem como pode ser instanciada por um vasto arranjo de verbos que se integram com ela. Por esse motivo, deve ser tomada em termos de continuum, uma vez que há sentidos que carregam atributos mais próximos do exemplar prototípico (como o agentividade e afetamento), enquanto outros se afastam sobremaneira. Os sentidos da CT se unem direta ou indiretamente ao exemplar prototípico, ou seja, o sentido A 
é o mais esquemático, uma vez que licencia um conjunto maior de verbos; já o sentido F, mais periférico, pode não ser predizível do exemplar prototípico, mas é motivado, em alguma medida por ele (LAKOFF, 1987).

Em consonância com o que postula Bybee (2010), grande parte das construções é parcialmente esquemática, com posições que podem ser ocupadas por um grupo de elementos semanticamente definidos. Nessa ótica, a CT pode ser agrupada por itens lexicais variados, que desempenham papéis semânticos previstos, ora licenciados pela construção, ora licenciados pelo verbo.

Ancorando-se na LFCU, postulou-se, aqui, que a motivação para o agrupamento de diferentes instanciações da CT está relacionada a elos de polissemia, que, em síntese, correspondem aos elos semânticos que ligam diferentes instanciações de uma construção, desde o sentido prototípico até suas extensões. Sob esse viés, o sentido central da CT [X afetar Y] é estendido para abarcar outros sentidos relacionados, configurando-se, assim, um caso de polissemia construcional. É por essa razão que a moldura sintática e as particularidades semânticas da construção são independentes dos verbos que podem ser licenciados por e fundidos com ela. Traugott e Trousdale (2013) assinalam que a construção pode facultar verbos de domínios semânticos relativamente distintos, isso porque o significado dos padrões construcionais é mais esquemático do que o significado do verbo, como é o caso da CT.

Goldberg (2006) elucida que instanciações com alta frequência fornecem ancoragem cognitiva, ou protótipo, que ajuda os usuários da língua a assimilar novos casos para a categoria. Assim, a alta frequência de instanciações com verbos de ação-processo, as quais naturalmente são mais concretas e correspondem à cena transitiva mais prototípica, permite ao usuário da língua estender o padrão para outros sentidos distintos, mas relacionados, e menos frequentes. Isso significa que os sentidos são arrolados no continuum, de modo que entre um e outro, novos sentidos podem emergir.

\section{Considerações finais}

Este artigo buscou discutir aspectos cognitivo-interacionais referentes às instanciações da Construção Transitiva. Para tanto, ancorou-se teoricamente aos postulados básicos da Linguística Funcional Centrada no Uso, alinhando-se à Gramática de Construções. Para compor a análise, foram examinados dados empíricos produzidos por usuários do português brasileiro.

Ao longo deste trabalho, foi possível observar que a manifestação discursiva da CT está 
diretamente relacionada a elos de polissemia entre as instanciações da construção. O sentido central da CT, (alguém age intencionalmente a fim de causar uma mudança numa entidade paciente), reflete uma cena básica da experiência humana e se liga, assim, ao padrão prototípico da categoria.

A frequência de uso do padrão prototípico permite ao usuário da língua realizar generalizações que podem ser estendidas para outros membros, isso porque, ao se deparar com um uso novo, o usuário, por economia, tende a recuperar uma representação armazenada em sua memória e associá-la a um item novo (BYBEE, 2010). Isso permite que a CT estenda seu sentido básico, construindo redes polissêmicas para abarcar novos sentidos, ou seja a forma é pareada com sentidos diversos. Essas redes CT são resultado dos processos cognitivos de domínio geral que subjazem qualquer atividade humana.

O fato de o sentido central da CT ser estendido para compreender outros corrobora a assunção de que as construções de uma língua são padrões da experiência, isto é, esquemas cognitivos que implicam procedimentos, em grande medida, rotinizados para que os usuários da língua atinjam seus objetivos comunicativos específicos.

\section{REFERÊNCIAS}

BORBA, F. S. (1996). Uma gramática de valências para o português. São Paulo: Ática.

BYBEE, J. (2010) Language, usage and cognition. Cambridge: United Kingdon University Press.

CEZARIO, M. M.; FURTADO DA CUNHA, M. A. (Orgs.). (2013) Linguística centrada no uso: uma homenagem a Mário Martelotta. Rio de Janeiro: Mauad X/FAPERJ.

CHAFE, W. (1979) Significado e estrutura linguística. Rio de Janeiro: Ao Livro Técnico.

CANÇADO, M. (2005). Manual de semântica: noções básicas e exercícios. Belo Horizonte: Ed. UFMG.

CÍRIACO, L. (2011). A hipótese do contínuo entre o léxico e a gramática e as construções incoativa, medial e passiva do PB. Tese (Doutorado em Estudos Linguísticos) - Faculdade de Letras, Universidade Federal de Minas Gerais, Belo Horizonte. 
CROFT, W. (2001). Radical Construction Grammar: syntactic theory in typological perspective. Oxford: Oxford University Press.

CUNHA, C.; CINTRA, L. (1985). Nova gramática do português contemporâneo. Rio de Janeiro: Nova Fronteira.

DU BOIS, J.; KUMPF, L.; ASHBY, W. (Eds.). (2003). Preferred Argument Structure: Grammar as Architecture for Function. Amsterdam: Benjamins.

FERRARI, L. (2011). Introdução à Linguística Cognitiva. São Paulo: Contexto.

FILLMORE, C. (1968). The case for case. In: BACH, E.; HARMS, R. (Orgs).Universals in linguistic theory. New York: Holt, Rinnehart and Winston.

. (1977). Topics in lexical semantics. In: COLE, R. (Ed). Current issues in linguistic theory. Bloomington: Indiana University Press.

. (1988). On grammatical construction. California: UCB.

FILLMORE, C.; KAY, P.; O'CONNOR, C. (1988). Regularity and Idiomaticity in Grammatical Constructions: The Case of Let Alone. Language, n. 64, p. 501-538.

FREGE, G. (2009). Lógica e Filosofia da Linguagem. São Paulo: EDUSP.

FURTADO DA CUNHA, M. A. (Org.). (1998). Corpus Discurso \& Gramática - a língua falada e escrita na cidade do Natal. Natal: EDUFRN.

. (2009). A transitividade em gêneros textuais narrativos: implicações para o ensino. In: SIGET, V, Natal. Anais... O ensino em foco. Caxias do Sul: EDUCS. p. 70-86.

. (2015). O estatuto argumental do objeto indireto e a construção ditransitiva no português do Brasil. In: FURTADO DA CUNHA, M. A. (Org). A gramática da oração-diferentes olhares. Natal: EDUFRN, p.135-165.

FURTADO DA CUNHA, M. A.; BISPO, E.; SILVA, J. R. (2013). Linguística funcional centrada 
no uso: conceitos básicos e categorias analíticas. In: CEZARIO, M. M; FURTADO DA CUNHA, M. A. (Orgs.). Linguística centrada no uso: uma homenagem a Mário Martelotta. Rio de Janeiro: Mauad X/FAPERJ, p. 13-39.

GIVÓN, T. (2001). Syntax. v. 1. Amsterdam: John Benjamins.

GOLDBERG, A. E. (1995). A construction grammar approach to argument structure. Chicago: University of Chicago Press.

. (2006). Constructions at work: the Nature of Generalization in Language. New York: Oxford University Press.

LAKOFF, G. (1977). Linguistic gestalts. Chicago: Chicago Linguistic Society. . (1987). Women, fire and dangerous things: what categories reveal about mind. Chicago: University Chicago Press.

LANGACKER, R. (2008). Cognitive Grammar: a basic introduction. Oxford: Oxford University Press.

NEVES, M. H. M. (2000). Gramática de usos do português. São Paulo: Editora UNESP.

OLIVEIRA, N. F. (2009). Abordagem cognitiva dos deverbais em -dor. Tese (Doutorado em Letras - Lingüística Aplicada), Programa de Pós-Graduação em Estudos da Linguagem, UFRN, Natal.

ÖSTMAN, J.; FRIED, M. (Ed). (2005). Construction grammar: cognitive grounding and theoretical extensions. Amsterdam/Philadelphia: John Benjamins.

PERINI, M. (1995). Gramática descritiva do português. São Paulo: Editora Ática.

RODRIGUES, A. (2006). Eu fui e fiz esta tese: as construções do tipo foi fez no Português do Brasil. 2006. Tese (Doutorado em Letras), Unicamp/IEL, Campinas.

ROSÁRIO, I. C.; OLIVEIRA, M. R. (2016). Funcionalismo e abordagem construcional da Gramática. Rev. Alfa. São Paulo, 60 (2), p. 233-259. 
SAID ALI, M. (1971). Gramática histórica da língua portuguesa. Rio de Janeiro: Edições Melhoramentos.

SALOMÃO, M. M; MIRANDA, N. (Orgs.). (2009). Construções do português do Brasil: da gramática ao discurso. Belo Horizonte: EDUFMG.

TALMY, L. (1988). Force dynamics in language and cognition. Cognitive Science, v. 2.

TAYLOR, J. (2003). Linguistic categorization. New York: Oxford University Press.

THOMPSON, S. A.; HOPPER, P. (2001). Transitivity, clause structure, and argument structure: evidence from conversation. In: BYBEE, J.; HOPPER, P. (Eds.). Frequency and the emergency of linguistic structure. Amsterdam: John Benjamins.

TOMASELlO, M. (Ed). (1998). The new psychology of language cognitive and functional approaches to language structures. New Jersey: Lawrence Erlbaum, v. 1.

. (Ed). (2003). The new psychology of language cognitive and functional approaches to language structures. New Jersey: Lawrence Erlbaum, v. 2.

. (2005). Constructing a language: a Usage-Based Theory of Language Acquisition. Cambridge: Harvard University Press.

TORRENT, T. T. (2008). A Construção de dativo com infinitivo: uma abordagem sociocognitivista e diacrônica. Veredas, v. 1, Juiz de Fora, p. 95-111.

TRAUGOTT, E. (2008). Grammaticalization, constructions and the incremental development of language: suggestions from the development of degree modifiers in English. In: ECKARDT, R.; JÄGER, G.; VEENSTRA, T. (Eds). Variation, Selection, Development-Probing the Evolutionary Model of language Change. Berlin/New York: Mouton de Gruyter, p. 219-250.

TRAUGOTT, E.; TROUSDALE, G. (2013). Constructionalization and constructional changes. New York: Oxford University Press. 